\title{
ADOLESCENT REPRODUCTIVE HEALTH SERVICES IN JIMMA CITY: ACCESSIBILITY AND UTILIZATION
}

\author{
Ayalew Tegegn, MD, MCommH, Yeshigeta Gelaw, MD, MMed
}

\begin{abstract}
BACKGROUND: Accessibility of health services for reproductive health (RH) is an important factor in increasing use of reproductive health services. Reports show that reproductive health services access in Ethiopia varies by region. A better understanding of the accessibility and utilization of existing reproductive health services by adolescents will help to address gaps with respect to provision of youth friendly services. The objective of this study was to assess the access to and the utilization status of RH services by adolescents in the age group of 15-19 years in Jimma City.

METHODS: A community-based cross-sectional study was conducted in Jimma City, Southwest Ethiopia from February to March 2004. Structured questionnaire was used to collect data from the sampled population. Adolescents aged between 15 to 19 years were interviewed about their accessibility and utilization of reproductive health services. The data were entered into two different computers using SPSS for windows version 12.0.1 and analyzed using STATA 9.1. Descriptive, bivariate analysis and logistic regression were employed to analyze the data.

RESULTS: Ninety five percent of adolescents could access Information, Education and Communication with very easy access and easy accessibility. However, 465(43\%) of adolescents had difficulty (difficulty and great difficulty) to access abortion care. Almost all mean index of the variables were close to the mean and midpoint of the accessible average index (2.09 $\pm S D=0.52)$. Among 1082 adolescents, 445(41.1\%), and 375(34.7\%) were ever and current users of reproductive health services, respectively. Among socio-demographic and economic predictors, age and means of communication in the households showed a significant association with utilization of reproductive health services $(p<0.05)$. Significant association was observed between utilization and knowledge about reproductive health services and source of information $(p<0.05)$.

CONCLUSION: The majority of adolescents were not utilizing reproductive health services. Thus, much more intensified effort is required to increase for each the reproductive health service utilization of adolescents. There should be health promotion activities for adolescent in order to improve the accessibility of the services and utilizations or reproductive services.
\end{abstract}

KEYWORDS: accessibility, utilization, reproductive health, adolescent, Jimma

\section{INTRODUCTION}

Approximately 1.2 billion adolescents live the world, of which nearly 900 million are in developing countries (1). Several countries in Sub-Saharan Africa (SSA) including Ethiopia have large and increasing adolescent populations that exceed those from other parts of the world $(1,2)$. Adolescents in Ethiopia were estimated to be $19.3 \%$ of the total population (2).

The fact that they have a large and significant share of the worlds' population, make it important to address their problem. More than 33 percent of the disease burden and almost 60 percent of premature deaths among adults can be associated with behaviors or conditions that began or occurred during adolescence for example sexual abuse and risky sex (3). The major health problems of adolescents include STDs, HIV/AIDS, absence of family planning method choice, unwanted pregnancy, lack of abortion care services, mental illnesses, crime and violence (3).

Adolescence has been described as a critical developmental period in the life course with major changes occurring in biological, cognitive, psychological, social and environmental processes, exploratory behavior and experimentation with a wide range of behaviors that are essential for normal adolescent development. Many of the avoidable problems in reproductive health $(\mathrm{RH})$, such as unwanted pregnancy, abortion and its complications, sexually transmitted infections (STIs) including the acquired immunodeficiency syndrome (AIDS) require for various preventive strategies to be put in place. Reproductive health is an important aspect of health, as it impinges on quality of life, especially for women (4).

\footnotetext{
${ }^{1}$ Department of Epidemiology \& Biostatistics, P.O. Box 1348, Jimma University, e-mail ayalewtm@yahoo.com

${ }^{2}$ Department of Ophthalmology, P.O. Box 378 Jimma University
} 
Knowledge about the availability of health services, little information about service availability, transportation and distance, confidentiality, ability to pay, parental notification rules and lack of differential centers remain important issues affecting adolescents' access (5). Most health services for adolescents are designed for adults and do not always have favorable conditions to meet the special needs of adolescents. This is, in part, because adolescents' accesses to the services are not clearly understood by themselves and service providers (5). For the proper planning of appropriate health services for adolescents, it is crucial to have knowledge of the pattern of their use.. At the moment, there is little information about the extent to which adolescents utilize available health services in Ethiopia as most studies that examined the use of health services had primarily focused on adults (6).

Studies conducted among adolescents in developed countries reported a high utilization rate of modern health services $(\underline{7}, \underline{8})$. Accessibility of reproductive health services is an important factors their utilization (5). A better understanding of the accessibility and utilization of $\mathrm{RH}$ services by adolescents will help to address the gaps in provision of youth friendly services. Therefore, the aim of this study was to assess accessibility and ever and current utilization of $\mathrm{RH}$ services and identify their predictors among adolescents 15 to 19 years old in Jimma City, South west Ethiopia.

\section{SUBJECTS AND METHODS}

The study was conducted in Jimma City, which is 357 $\mathrm{km}$ away from Addis Ababa. The study period was from February to March 2004. Detailed information about study community setting was described elsewhere (9).

This paper is part of a study conducted to assess Reproductive Health Knowledge and Attitude among Adolescents in Jimma City (9). The study participants were adolescents of 15 to 19 years old who resided in the study area for at least six months. From the 1994 census, the total projected adolescents living in Jimma City were 27,140. The sample size was determined using Epi Info Version $6.04 \mathrm{~d}$ statistical package for estimating single population proportions. We assumed $50 \%$ proportion with $95 \%$ confidence level and 3\% margin of error to get a maximum sample size. On the calculated sample size of 1027 , twenty percent was added for non-response giving a total sample size of 1128 . From 21 kebeles (smallest administrative unit) that of Jimma City, 9 were randomly selected and included. The sample was allocated proportional to the adolescent population size of each Kebele. The first respondent from each Kebele was identified using lottery method and then systematic sampling technique was used to identify the other respondents and followed North, east, south and West directions at interval of every seventh households.
A structured questionnaire was developed and administered to the respondents. The questionnaire and consent documents were developed in English then translated into Amharic language and finally back translated into English by another translator. Interviewers were recruited and underwent two days training that included cognitive interviewing, practice interviewing, and role playing After two days training, interviewers undertook a pre-test was conducted Following the pretesting, interviewers and investigators met to discuss experiences, issues, and resolve questionnaire problems. Pre-test data were also checked for consistency, outliers, and missing values. Upon completion of the pre-testing, one day follow-up training was conducted with a focus on resolving issues, allowing interviewers to share experiences, and finalizing the questionnaires. Interviews were conducted in private place. In the case of more than one adolescent in the households, lottery method was used to recruit only one.; for households, in which the adolescent was not found at home three visits were made before considering them as non-respondent. Oral consent was obtained from either parent (mother or father) if they agree of interviewing their son or daughter. Oral consent was also obtained from each interviewee for their agreement to participate in the study. However, the adolescents were assured that neither the interviewer nor their parents would have access to their responses. Privacy, anonymity and confidentiality were maintained throughout the process of the study. The domain of the study covers accessibility and utilization of health services for medical check up, sexually infection treatment, voluntary counseling and testing, family planning, IEC and abortion care by adolescents of age 15 to 19 years. The responses for accessibility, which ranged from "very easy access" to "access with great difficulty" were converted into four-point scales. A summary mean index provides the average scores for the accessibility

Data were entered, cleaned and stored into two different computers, using SPSS for windows version 12.0.1 and analyzed using STATA 9.1. Descriptive, bivariate and logistic regression analysis was employed. Descriptive statistics were calculated for all variables. Independent t-test was done to see compare accessibility means. In bivaraite analysis crude odds ratio and confidence interval were determined. Logistic regression was used to determine the adjusted odds ratio and corresponding confidence interval. Maximum likelihood estimates of the independent effect of the predictor variables and Wald test statistics for a single parameter estimate were used to see the level of significance. The strength of association was interpreted using the adjusted odds ratio and $95 \% \mathrm{CI}$. The criterion for statistical significance was set at 0.05 . 
The following operational definitions were used;

Reproductive health services is the services provided for adolescent such as abortion and postabortion care, IEC, family planning, VCT, medical check up, sexual transmitted infection treatment and likes

Accessibility: defined as the sum of economic, physical (geographical), cultural accessibility and not merely the physical presence of reproductive health services

Very easy accessibility: adolescent can access the reproductive health services without any problem.

Easy accessibly: Adolescent access reproductive health services with minor difficulty

\section{RESULTS}

Complete data were available for 1082 adolescents out of 1128 sampled households, yielding a response rate of $96 \%$. Demographic and socioeconomic information of study participants were explained elsewhere (9). As shown in figure 1 , almost $95 \%$ of adolescents accessed information Education and communication (IEC) with very easy access and easy accessibility. However, $465(43 \%)$ of adolescents had difficulty (difficulty and great difficulty) to access abortion care (Fig 1).

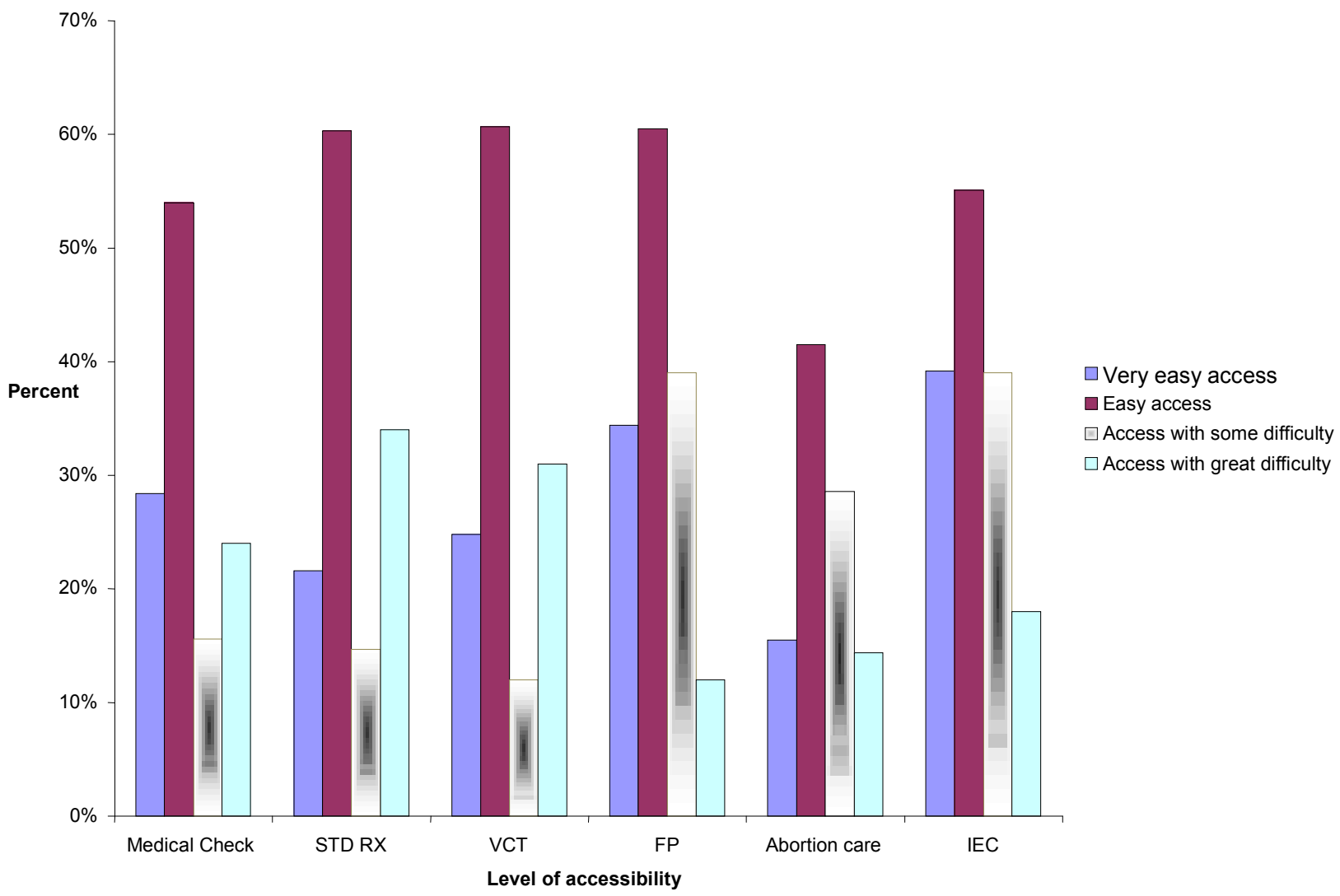

Figure 1. Level of accessibility to RH services for adolescents of age 15-19 years, Jimma City, Southwest Ethiopia, March, 2004. 
Table 1. Mean scores of adolescent of age 15-19 years on index cultural accessibility to reproductive health services use by the selected characteristics, Jimma City, Southwest Ethiopia, March, 2004.

\begin{tabular}{|c|c|c|}
\hline Characteristics & Access mean score & P-value \\
\hline Overall mean & 2.10 & \\
\hline \multicolumn{3}{|l|}{ Age } \\
\hline $15-17$ & 2.12 & \\
\hline $18-19$ & 2.06 & 0.0505 \\
\hline \multicolumn{3}{|l|}{ Sex } \\
\hline Female & 2.09 & \\
\hline Male & 2.11 & 0.5627 \\
\hline \multicolumn{3}{|l|}{ Marital status } \\
\hline Single & 2.10 & \\
\hline Ever married & 1.97 & 0.0969 \\
\hline \multicolumn{3}{|l|}{ Ethnic group } \\
\hline Oromo & 2.08 & \\
\hline Others & 2.11 & 0.4193 \\
\hline \multicolumn{3}{|l|}{ Religion } \\
\hline Muslim & 2.06 & \\
\hline Christian & 2.12 & 0.0677 \\
\hline \multicolumn{3}{|l|}{ Educational status } \\
\hline Elementary and less & 2.29 & \\
\hline Above elementary & 2.09 & 0.0040 \\
\hline \multicolumn{3}{|l|}{ Occupational status } \\
\hline Student & 2.09 & \\
\hline Others category & 2.14 & 0.3277 \\
\hline \multicolumn{3}{|l|}{ Family size } \\
\hline Five and less family size & 2.10 & \\
\hline Above five family size & 2.09 & 0.6099 \\
\hline \multicolumn{3}{|l|}{ Radio } \\
\hline No & 2.22 & \\
\hline Yes & 2.09 & 0.0158 \\
\hline \multicolumn{3}{|l|}{ Television } \\
\hline No & 2.12 & \\
\hline Yes & 2.08 & 0.2541 \\
\hline \multicolumn{3}{|l|}{ Telephone } \\
\hline No & 2.10 & \\
\hline Yes & 2.09 & 0.7367 \\
\hline \multicolumn{3}{|l|}{ Newspaper } \\
\hline No & 2.16 & \\
\hline Yes & 2.045 & 0.0002 \\
\hline \multicolumn{3}{|c|}{ Ever utilization of services for $\mathrm{RH}$} \\
\hline No & 3.01 & \\
\hline Yes & 2.93 & 0.0000 \\
\hline \multicolumn{3}{|l|}{ Current user of RH } \\
\hline No & 3.01 & \\
\hline Yes & 2.93 & 0.0000 \\
\hline
\end{tabular}

Table 1 shows the bivariate relationships between demographic, socioeconomic characteristics, means of functional communication, history of health services utilization for RH with the summary index of cultural accessibility. Among all participants, the mean score on the 6-point type of health services for $\mathrm{RH}$ with four scales of response ranging from 1 (very easy accessibility) to 4 (accessibility with great difficulty) were indexed and then averaged; The mean score of
$2.09(\mathrm{SD}=0.52)$ falls near the midpoint of the index. Almost all mean indexes of the variables were close to the mean and midpoint of the accessible average index. However, those who had better education, those who had functional radio and newspaper as means of communication displayed relatively more accessibility to RH services $(\mathrm{P}<0.05)$. Adolescents who were ever users or current users of $\mathrm{RH}$ services had on average better access than those who never and not using currently 
$(\mathrm{P}<0.0000)$.

Table 2. life time and current utilization of health services for RH by the study subjects, Jimma City, Southwest Ethiopia, March, 2004.

\begin{tabular}{|c|c|c|}
\hline RH utilization & Frequency & Percent \\
\hline RH service ever utilized & 445 & 41.1 \\
\hline \multicolumn{3}{|l|}{ Frequency of utilization $(n=445)$} \\
\hline Always & 51 & 4.2 \\
\hline mostly & 59 & 5.5 \\
\hline Occasional & 335 & 31.0 \\
\hline \multicolumn{3}{|l|}{ Place of services obtained for $R H$} \\
\hline Government hospital & 243 & 22.5 \\
\hline Health center & 251 & 23.2 \\
\hline private clinic & 177 & 16.4 \\
\hline Red cross & 171 & 15.8 \\
\hline FGAE & 299 & 27.6 \\
\hline Pharmacy & 131 & 12.1 \\
\hline Traditional healers & 34 & 3.1 \\
\hline Others (community health workers etc) & 83 & 7.7 \\
\hline \multicolumn{3}{|l|}{ Reason for visiting $R H$ providers in the past } \\
\hline Medical Checkup & 175 & 16.2 \\
\hline STI treatment & 49 & 4.5 \\
\hline VCT & 179 & 16.5 \\
\hline FP & 190 & 17.6 \\
\hline Abortion care & 34 & 3.1 \\
\hline IEC & 370 & 34.2 \\
\hline Current RH utilization & 375 & 34.7 \\
\hline \multicolumn{3}{|l|}{$\begin{array}{l}\text { Types of service being rendered at the } \\
\text { moment }\end{array}$} \\
\hline Medical Check UP & 164 & 15.2 \\
\hline STD treatment & 40 & 3.7 \\
\hline VCT & 147 & 13.6 \\
\hline FP & 176 & 16.3 \\
\hline Abortion care & 26 & 2.4 \\
\hline IEC & 312 & 28.8 \\
\hline \multicolumn{3}{|l|}{ Places of current RH services } \\
\hline Government hospital & 243 & 22.5 \\
\hline Health center & 240 & 22.2 \\
\hline private clinic & 166 & 15.3 \\
\hline Red cross & 169 & 15.6 \\
\hline FGAE & 289 & 26.7 \\
\hline Pharmacy & 128 & 11.8 \\
\hline Traditional healers & 22 & 2.0 \\
\hline Others & 44 & 4.1 \\
\hline \multicolumn{3}{|l|}{ Reason for not using RHS } \\
\hline Don't need now & 235 & 21.7 \\
\hline Never thought of & 58 & 5.4 \\
\hline I am too young & 207 & 19.1 \\
\hline Lack of knowledge & 144 & 13.3 \\
\hline Time constraint & 83 & 7.7 \\
\hline I don't want to use & 63 & 5.8 \\
\hline
\end{tabular}

Among 1082 adolescents, 445(41.1\%), and $375(34.7 \%)$ of the adolescents were ever and current users of RH services, respectively. For ever users, RH services were sought from Family Guidance Association of Ethiopia (FGAE) 299 (27.6\%), governmental health center $251(23.2 \%)$ and governmental hospital 243 
(22.5\%). Traditional health services were sought for 34 (3.1\%) of adolescents. Thirty four percent (370) of adolescents ever used health services for Information, Education and Communication (IEC) followed by family planning 190 (17.6\%). Five percent (49) and 34(3.1\%) of them used health services for Sexually Transmitted Infections (STI) treatment and abortion care, respectively. During the study period, 312(28.8), $176(16.3 \%)$ and $164(15.2 \%)$ were current users of IEC , family planning service and medical check-up, respectively. Twenty seven percent (289) of adolescents received the health services for RH from FGAE of Jimma City followed by Jimma Specialized Hospital 243(22.5 \%) and Jimma Health Center 240(22.2\%). For current use of health services for $\mathrm{RH}$, traditional health services were sought for $22(2.0 \%)$ of adolescents. Adolescents who never used RH services were 537(58.9\%). Adolescents who did not seek any RH service were asked to give reasons for not using health services. The main reasons mentioned were that they do not need it at the moment $235(21.7 \%)$ and considering themselves as being young to use RH services 207 (19.1\%) (Table 2).

Age group of 18 to 19 years were $44 \%$ times more likely to ever use RH services than those in the age group of 15 to 17 years old after adjusting for other predictors ( adjusted OR=1.4 95\% CI $(1.10,1.9)$. The availability of functional television and telephone in the households were associated with reduced ever use of health services for $\mathrm{RH}$ by adolescents when adjusted for covariates [adjusted $\mathrm{OR}=0.795 \% \mathrm{CI}(0.5,0.9)$, adjusted $\mathrm{OR}=0.7$ $95 \%$ CI $(0.5,0.9)$ respectively]. On the other hand, adolescents in the households with functional radio and access to Newspaper were likely to ever use RH services [adjusted $\mathrm{OR}=1.7,95 \% \mathrm{CI}(1.1,2.7)$, adjusted $\mathrm{OR}=2.5$ 95\% CI $(1.9,3.3)$, respectively] (Table 3).

Table 3. Crude and adjusted odds ratio (95\% confidence intervals) from bivariate and logistic regression analysis of factors associated with ever utilization of health services for RH, Jimma City, Southwest Ethiopia, March, 2004.

\begin{tabular}{|c|c|c|c|c|}
\hline Characteristics & Unadjusted OR(95\%CI) & $P$-value & adjusted OR $(95 \% \mathrm{CI})$ & $P$-value \\
\hline \multicolumn{5}{|l|}{ Age group } \\
\hline $15-17$ & 1.0 & & 1.0 & \\
\hline $18-19$ & $1.5(1.2,1.9)$ & 0.0011 & $1.4(1.1,1.9)$ & 0.007 \\
\hline \multicolumn{5}{|l|}{ Sex } \\
\hline Female & 1.0 & & & \\
\hline Mae & $0.9(0.7,1.1)$ & 0.2795 & NS & \\
\hline \multicolumn{5}{|l|}{ Marital status } \\
\hline Single & 1.0 & & 1.0 & \\
\hline Ever married & $2.5(1.3,4.5)^{*}$ & 0.0033 & $1.5(0.8,3.0)$ & 0.240 \\
\hline \multicolumn{5}{|l|}{ Ethnic group } \\
\hline Oromo & 1.0 & & & \\
\hline Others & $1.0(0.8,1.3)$ & 0.8903 & NS & \\
\hline \multicolumn{5}{|l|}{ Religion } \\
\hline Muslim & 1.0 & & & \\
\hline Christian & $1.0(0.7,1.2)$ & 0.7075 & NS & \\
\hline \multicolumn{5}{|l|}{ Educational status } \\
\hline Elementary school and less & 1.0 & & & \\
\hline Above elementary school & $1.4(0.8,2.4)$ & 0.2611 & NS & \\
\hline \multicolumn{5}{|l|}{ Occupation } \\
\hline Student & 1.0 & & 1.0 & \\
\hline Other category & $1.7(1.2,2.5)^{*}$ & 0.0033 & $1.3(0.9,2.0)$ & 0.195 \\
\hline \multicolumn{5}{|l|}{ Having functional radio } \\
\hline No & 1.0 & & 1.0 & \\
\hline Yes & $1.5(1.0,2.3)$ & 0.0699 & $1.7(1.1,2.7)$ & 0.031 \\
\hline \multicolumn{5}{|l|}{ Having functional television } \\
\hline No & 1.0 & & 1.0 & \\
\hline Yes & $0.7(0.5,0.8)^{* *}$ & 0.0006 & $0.7(0.5,0.9)$ & 0.013 \\
\hline \multicolumn{5}{|l|}{ Having functional telephone } \\
\hline No & 1.0 & & 1.0 & \\
\hline Yes & $0.6(0.5,0.8)^{* *}$ & 0.0000 & $0.7(0.5,0.9)$ & 0.009 \\
\hline \multicolumn{5}{|l|}{ Access to newspaper } \\
\hline No & 1.0 & & 1.0 & \\
\hline Yes & $2.4(1.8,3.1)^{* *}$ & 0.0000 & $2.5(1.9,3.3)$ & 0.000 \\
\hline
\end{tabular}

Adoloscents in the age group 18 to 19 years were $37 \%$ more likely to be current users compared to those 
15 to 17 years old (Adjusted OR=1.4 95\% CI $(1.1,1.8)$ after controlling other demographic and socioeconomic variable. Similar to ever use, adolescents from households with functional radio and access to Newspaper were more likely to be current users [Adjusted $\mathrm{OR}=1.7,95 \%$ CI $(1.02,2.7)$, adjusted $\mathrm{OR}=2.2,95 \%$ CI $(1.9,2.9)$, respectively] whereas adolescent from households with functional telephone were $34.0 \%$ times less likely to be current users [adjusted $\mathrm{OR}=0.7,95 \% \mathrm{CI}(0.5,0.9)]$ (Table 4$)$.

Knowledge about types of RH services showed significant association with ever use. Adolescents with knowledge of family planning and VCT services were 9 and 3 time more likely to ever use RH services, [adjusted OR $=8.9,95 \%(2.3$ 26.6)] and [adjusted $\mathrm{OR}=2.8 \quad 95 \%$ CI (1.5 5.3) respectively. Whereas adolescents who had knowledge of STI treatment as components of RH services $71.0 \%$ were less likely to

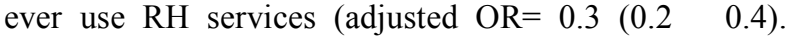
Adolescents who had interaction with family and peers and had access to pamphlets and posters as source of information for RH services were more likely to be ever user [adjusted $\mathrm{OR}=1.495 \% \mathrm{CI}(1.011 .8)$; adjusted $\mathrm{OR}=$ $2.895 \%$ CI $(1.96,3.9)$; adjusted $\mathrm{OR}=4.7,95 \%$ (3.7 $6.2)$; and adjusted $\mathrm{OR}=1.7,95 \%$ CI (1.2 2.3), respectively] (Table 5).

Tables 4. Crude and adjusted odds ratio ( $95 \%$ confidence intervals) from bivariate and logistic regression analysis of factors associated with current utilization of services for RH, Jimma City, Southwest Ethiopia, March, 2004.

\begin{tabular}{|c|c|c|c|c|}
\hline Characteristics & Unadjusted OR(95\%CI) & P-value & adjusted OR(95\% CI) & P-value \\
\hline \multicolumn{5}{|l|}{ Age group } \\
\hline $15-17$ & 1.0 & & 1.0 & \\
\hline $18-19$ & $1.4(1.14,1.8)$ & 0.0085 & $1.4(1.1,1.8)$ & 0.020 \\
\hline \multicolumn{5}{|l|}{ Sex } \\
\hline Female & 1.0 & & & \\
\hline Mae & $1.0(0.8,1.3)$ & 0.9462 & NS & \\
\hline \multicolumn{5}{|l|}{ Marital status } \\
\hline Single & 1.0 & & 1.0 & \\
\hline Ever married & $2.2(1.2,4.1)$ & 0.0072 & $1.7(0.9,3.1)$ & 0.111 \\
\hline \multicolumn{5}{|l|}{ Ethnic group } \\
\hline Oromo & 1.0 & & & \\
\hline Others & $0.9(0.7,1.2)$ & 0.5950 & NS & \\
\hline \multicolumn{5}{|l|}{ Religion } \\
\hline Muslim & 1.0 & & & \\
\hline Christian & $0.9(0.7,1.2)$ & 0.4438 & NS & \\
\hline \multicolumn{5}{|l|}{ Educational status } \\
\hline Elementary school and less & 1.0 & & & \\
\hline Above elementary school & $1.1(0.6,2.0)$ & 0.6848 & NS & \\
\hline \multicolumn{5}{|l|}{ Occupation } \\
\hline Student & 1.0 & & & \\
\hline Other category & $1.2(0.9,1.8)$ & 0.2650 & NS & \\
\hline \multicolumn{5}{|l|}{ Having functional radio } \\
\hline No & 1.0 & & 1.0 & \\
\hline Yes & $1.6(1.0,2.5)$ & 0.0481 & $1.7(1.0,2.7)$ & 0.042 \\
\hline \multicolumn{5}{|l|}{ Having functional television } \\
\hline No & 1.0 & & 1.0 & \\
\hline Yes & $0.9(0.6,1.00)$ & 0.0471 & $0.8(0.6,1.1)$ & 0.234 \\
\hline \multicolumn{5}{|l|}{ Having functional telephone } \\
\hline No & 1.0 & & 1.0 & \\
\hline Yes & $0.6(0.5,0.8)^{* *}$ & 0.0005 & $0.7(0.5,0.9)$ & 0.009 \\
\hline \multicolumn{5}{|l|}{ Access to newspaper } \\
\hline No & 1.0 & & 1.0 & \\
\hline Yes & $2.2(1.7,2.8)^{* *}$ & 0.0000 & $2.2(1.7,2.9)$ & 0.000 \\
\hline
\end{tabular}

$\mathrm{OR}=$ Odds ration, $\mathrm{CI}=$ Confidence interval, $*=\mathrm{p} .<0.05, * * \mathrm{p}<0.01, \mathrm{NS}=$ Non significant in unadjusted model 
Table 5. Crude and adjusted odds ratio ( $95 \%$ confidence intervals) from bivariate and logistic regression analysis of factors associated with ever utilization of health services for RH, Jimma City, Southwest Ethiopia, March, 2004.

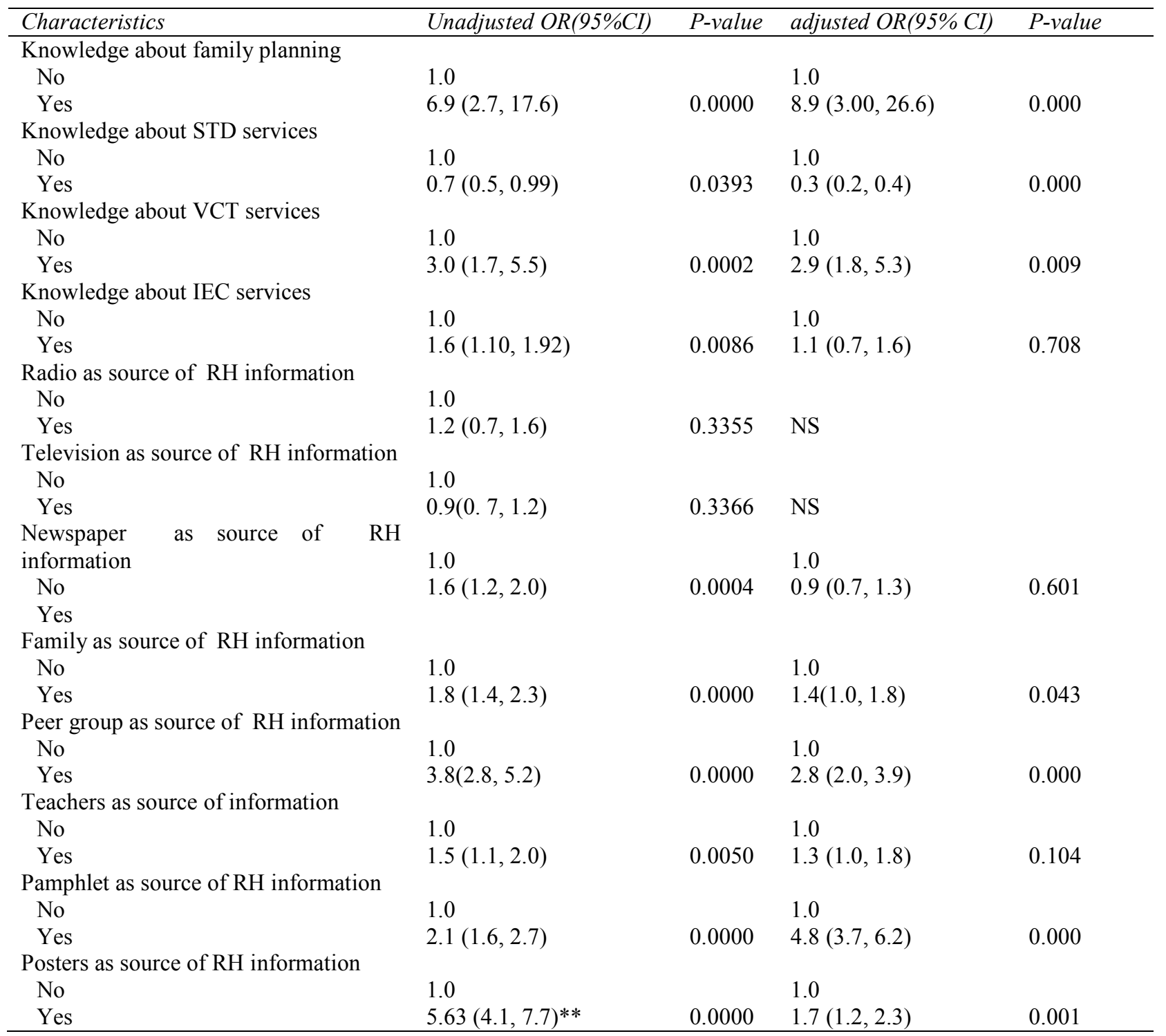

$\mathrm{OR}=$ Odds ration, $\mathrm{CI}=$ Confidence interval, $*=\mathrm{p} .<0.05$, ** $\mathrm{p}<0.01, \mathrm{NS}=$ Non significant in unadjusted model Adolescents with knowledge of family planning were 13 times more likely to be current user of $\mathrm{RH}$ services (adjusted OR=12.5, 95\% CI $(3.3,47.1)$, whereas adolescent with knowledge of STI treatment as components of RH services were $78 \%$ less likely to be current user [adjusted $\mathrm{OR}=0.2,95 \%$ CI $(0.2,0.4)$ ]. Adolescents who stated teachers, peers, pamphlets and posters as source of information for $\mathrm{RH}$ were more likely to be current users [Adjusted $\mathrm{OR}=1.8,95 \% \mathrm{CI}(1.3,2.4)$, Adjusted $\mathrm{OR}=2.8$, 95\% $\mathrm{CI}$ (2.1. 4.4), Adjusted $\mathrm{OR}=1.6$, 95\%CI $(1.1,2.2)$, Adjusted OR=2.2.8, 95\%CI $(1.6,3.0)$, Adjusted OR=3.4, 95\%CI $(2.5,4.7)$ (Table 6).

\section{DISCUSSION}

This study assessed a range of possible predictors, including demographic, socioeconomic as well knowledge about RH services. Majority of the respondents accessed the different components of health services provided in the locality easily. However, the overall mean accessibility of health services for RH was moderate. This study showed that the average index of accessibility of RH services was positively associated with higher educational status, presence of functional radio in the households, access to newspaper and history of $\mathrm{RH}$ services utilization. The finding implies that 
accessibility is a multidimensional concept that it is not psychological and attitudinal costs, cognition and the only limited to physical proximity and travel time to perceptions of potential clients (10).

services centers, but also involves economic,

Table 6. Crude and adjusted odds ratio (95\% confidence intervals) from bivariate and logistic regression analysis of factors associated with current utilization of health services for RH, Jimma City, Southwest Ethiopia, March, 2004.

\begin{tabular}{|c|c|c|c|c|}
\hline Characteristics & $\begin{array}{l}\text { Unadjusted } \\
\text { OR }(95 \% C I)\end{array}$ & $P$-value & $\begin{array}{l}\text { Adjusted } \\
\text { OR }(95 \% C I)\end{array}$ & $P$-value \\
\hline \multicolumn{5}{|c|}{ Knowledge about family planning } \\
\hline No & 1.0 & & 1.0 & \\
\hline Yes & $9.0(2.8,29.5)$ & 0.0000 & $12.5(3.3,47.1)$ & 0.000 \\
\hline \multicolumn{5}{|c|}{ Knowledge about STD services } \\
\hline No & 1.0 & & 1.0 & \\
\hline Yes & $0.6(0.6,0.8)$ & 0.0014 & $0.2(0.2,0.4)$ & 0.000 \\
\hline \multicolumn{5}{|c|}{ Knowledge about VCT services } \\
\hline No & 1.0 & & 1.0 & \\
\hline Yes & $2.5(1.3,4.6)$ & .0028 & $2.0(0.9,4.4)$ & 0.082 \\
\hline \multicolumn{5}{|c|}{ Knowledge about IEC services } \\
\hline No & 1.0 & & & \\
\hline Yes & $1.2(0.9,1.5)$ & 0.3223 & NS & \\
\hline \multicolumn{5}{|c|}{ Radio as source of RH information } \\
\hline No & 1.0 & & 1.0 & \\
\hline Yes & $2.7(1.9,3.9)$ & 0.0000 & $1.5(0.8,2.6)$ & 0.176 \\
\hline \multicolumn{5}{|c|}{ Television as source of $\mathrm{RH}$ information } \\
\hline No & 1.0 & & 1.0 & \\
\hline Yes & $1.5(1.1,2.0)$ & 0.0057 & $0.7(0.6,1.0)$ & 0.061 \\
\hline \multicolumn{5}{|c|}{ Newspaper as source of $\mathrm{RH}$ information } \\
\hline No & 1.0 & & 1.0 & \\
\hline Yes & $2.2(1.7,2.9)$ & 0.0000 & $1.4(1.0,1.9)$ & 0.059 \\
\hline \multicolumn{5}{|c|}{ Family as source of RH information } \\
\hline No & 1.0 & & 1.0 & \\
\hline Yes & $2.4(1.8,3.1)$ & 0.0000 & $1.8(1.3,2.4)$ & 0.000 \\
\hline \multicolumn{5}{|c|}{ Peer group as source of $\mathrm{RH}$ information } \\
\hline No & 1.0 & & 1.0 & \\
\hline Yes & $3.9(2.8,5.5)$ & 0.0000 & $1.8(2.1,4.4)$ & 0.000 \\
\hline \multicolumn{5}{|c|}{ Teachers as source of information } \\
\hline No & 1.0 & & 1.0 & \\
\hline Yes & $1.9(1.4,2.5)$ & 0.0000 & $1.6(1.10,2.2)$ & 0.013 \\
\hline \multicolumn{5}{|c|}{ Pamphlet as source of $\mathrm{RH}$ information } \\
\hline No & 1.0 & & 1.0 & \\
\hline Yes & $2.8(2.2,3.7)$ & 0.0000 & $2.2(1.6,3.0)$ & 0.000 \\
\hline \multicolumn{5}{|c|}{ Posters as source of RH information } \\
\hline No & 1.0 & & 1.0 & \\
\hline Yes & $4.4(3.3,5.9)^{\S}$ & 0.0000 & $3.4(2.5,4.7)$ & 0.000 \\
\hline
\end{tabular}

$\mathrm{OR}=$ Odds ration, $\mathrm{CI}=$ Confidence interval, $*=\mathrm{p} .<0.05,{ }^{\S} \mathrm{p}<0.01, \mathrm{NS}=$ Non significant in unadjusted model

Ever use of RH services is basically measured as the cumulative experience of adolescents with $\mathrm{RH}$ services (11). In this study the ever use of RH services was found to be $41.1 \%$; however, the current utilization of RH services, elicited by asking past three months use of RH services from the date of interview, was found to be lower than the ever use (34.7\%). Both Ever and current utilization rate of overall $\mathrm{RH}$ services were considerably lower as compared to a report from Tanzania where $75 \%$ of adolescents used health services for RH (12) and the developed world experiences $(7,8)$. In this study, despite better access to health services, adolescents' utilization of health services is low. In a study conducted in Addis Ababa, considerable proportion 
of the adolescents reported that existing health services are inaccessible, unaffordable and unacceptable. The major barriers to utilizing reproductive health services are feeling of embarrassment and fear of being seen by parents or people who know them (13). This indicates that geographic accessibility does not imply utilization of health services. This is also evidenced by other study carried out in Ethiopia where adolescents with accessible family planning services $(100 \%$ the geographic coverage and the availability of all levels of health institutions), the prevalence of unintended pregnancy was relatively high $(33.3 \%)(14)$.

The findings in our study indicated that adolescents used various options of health services similar to those previous report among adults in Ethiopia (15) and elsewhere in Africa $(12,16)$. This study showed that a small proportion $(3.14 \%$ among ever users and 2.03 of current users) of the adolescents used a traditional health service which is slightly lower than reports from other parts of this country (15). This could be explained in several ways; first, the study addresses more culturally sensitive reproductive health issues such as STI and HIV/AIDS as compared to other studies and secondly, the sample was from an urban area, where usually there is a relatively high number and options of health facilities for RH services and easier geographic access compared to other findings from rural areas. Thirdly, adolescents might have underreported use of traditional healers (such as in the case of abortion services) which is supported by the fact that only $3.2 \%$ and $2.4 \%$ of adolescents declared as ever user and current user, respectively of health services for abortion care in contrast to other reports $(17,18)$.

Other demographic and socio-economic variables such as education level and schooling do not show statistical significant association with ever or current use of RH services. This finding is not in agreement with other studies in Ethiopia $(6,19,20)$. This might be due the fact that this study was focused only in town where they had betted access to education. However, adolescents within age groups of 18 to 19 years were more likely to ever and currently use health services than adolescents of age 15 to 17 years. This is in line with other finding from Northwest Ethiopia where older age groups were more likely to use family planning services than younger age group when adjusted for other covariates (21). Adolescents from the households with radio and newspaper as means of communication were more likely to ever and currently use health services than those without these means of communications when controlled for other covariates. This might due to the fact that both means of communication can be owned by all class (both the poor and the richer social group.

On the other hand, adolescents from households with television and telephone as means of communication were less likely to ever or currently use health services for $\mathrm{RH}$ than adolescents without these means of communications. This might be explained by the fact that adolescents from households with television and telephones might be from high socio-economic status (possession of telephone and televisions as indicator of better economic status) and as a result perceived as lower risk for reproductive health problems. Poor adolescents bear a disproportionate burden of the reproductive health problems in their age group. There is a strong association between poverty and the health status of adolescents and between poverty and adolescents' use of health services. For the poorest 20 percent of young women are between 1.7 and 4.0 times as likely to have an early birth as the richest 20 percent of young women. Similar disparities between rich and poor adolescents are seen for indicators such as early marriage, skilled attendance at birth, use of contraception, and HIV/AIDS transmission (4). This might have resulted in an apparent better utilization of RH services by those adolescents from households without television and telephone.

Variables related with knowledge of RH services are associated with ever and current utilization of health services for reproductive health. Adolescents with knowledge of VCT for HIV/AIDS were three times more likely to ever use RH services than adolescents with no such knowledge when other covariates were controlled. Unlike our finding, the study in Addis Ababa showed that knowledge about VCT was not associated with use of health services for pre-marital screening (RH) (22). This difference could be due difference in respondent both in terms of demographical characteristics and the time difference these studies were conducted. On the other hand, adolescents with knowledge of STI treatment were less likely to ever and currently use health services for RH than those adolescents who were not aware of STI treatment as services for RH. This might be because those who knew STI treatment might have been treated as clandestine and may deny as if they do not know such $\mathrm{RH}$ problems. Adolescents with knowledge about family planning services were 9 and 13 times more likely to ever and currently use, RH services which could be explained by the fact that family planning services are delivered with a package of general awareness on RH so that those who were exposed to such information are more likely to be motivated for RH services ever or now.

On the other hand, peer groups as sources of $\mathrm{RH}$ information were more likely to ever or currently use RH services. This was evidenced by the finding that peer education reaches larger numbers of youth and documented greater increases in health services users (23). Similarly, a study carried out in Addis Ababa; showed that peer education has more coverage than youth centers appear to have limited coverage (24). Printed medias such as posters and pamphlets were also more likely to increase ever or current use of $\mathrm{RH}$ services. Printed media is an appealing strategy for 
Adolescent Reproductive Health (ARH) programs because of the potential to reach large numbers of youth and to introduce new ideas and the likelihood to increase the use of health services by adolescents. RH-related interventions directed specifically to adolescent audiences, communications research indicates that printed media can be an effective strategy for influencing adult reproductive health behaviors which perhaps holds true for adolescents (25).

In conclusion, this study has found out that majority of adolescents are not utilizing RH services despite the availability of a wide range of service giving centers in the city. It clearly indicates that cultural accessibility may have more importance for utilization of health services than physical accessibility, particularly for adolescent age groups. Interestingly, unlike many other studies, our study showed that the leaner relationship between knowledge of health problems and availability of health services with its utilization. The role of mass and printed media and that of peers had significant positive influence on the use of RH services by the adolescents.

However, much more intensified effort is required to increase the health service utilization for $\mathrm{RH}$ by the adolescents who are the prime victims for a range of $\mathrm{RH}$ problems for various reasons. More rigorous study that would single out the most pertinent factor(s) may be recommended to enable planners design youth friendly $\mathrm{RH}$ services in the city.

\section{ACKNOWLEDGEMENTS}

This study was financially supported by Research and Publication Office of Jimma University.

\section{REFERENCES}

1. UNICEF. The State of the World's Children 2004. New York: UNICEF; 2003. Available at: www.unicef.org/publications/Eng_text.pdf

2. Central Statistics Authority (CSA), Population Projection of Ethiopia: Total and Sectoral (1985-2035), Population Studies series No 2, Addis Ababa, Ethiopia, 1998.

3. EPHA. Adolescent reproductive health global and national initiatives and lessons learned, EPHA ARH Taskforce, August 2003.

4. Lule E, Rosen JE, Singh S, Knowles JC, Behrman JR. Adolescent Health Programs. In: Jamison DT, Breman JG, Measham AR, Alleyne G, Claeson, Evans David B (eds) Disease Control Priorities in Developing Countries in 2006: 1109-1125.

5. Klein JD, Wilson $\mathrm{KM}$, McNulty $\mathrm{M}$, et al. Access to medical care for adolescents: results from the 1997 Commonwealth Fund Survey of the Health of Adolescent Girls. J Adolesc Health, 1999; 25(2):120-30.
6. Fantahun M, Degu G. Health Service Utilization in Amhara Region of Ethiopia. Ethiop J Health Dev, 2003;17(2):141-147.

7. Ryan SA, Millstein SG, Greene $\mathrm{B}$, et al. Utilization of ambulatory health services by urban adolescents. Journal of Adolescent Health, 1996; 18: 192-202.

8. Aten MJ, Siegel DM, Roghmann KJ. Use of health services by urban youth: a school-based survey to assess differences by grade level, gender, and risk behavior. Journal of Adolescent Health, 1996;19:258-266.

9. Tegegn A, Yazachew M, Gelaw Y. Reproductive Health Knowledge and Attitude among Adolescents: A community based study in Jimma Town, Southwest Ethiopia. Ethiopian Journal of Health Development, 2008;22(3):243-25.

10. Bertrand JT, Magnani RJ. Angle M A. Access, quality of care and medical barriers in family planning programs. International Family Planning Perspectives, 1995; 21(2):64-74.

11. Central Statistical Agency (CSA)[Ethiopia] and ORC Macro. Ethiopia Demographic and Health Survey 2005. Addis Ababa, Ethiopia and Calverton, Maryland, USA: CSA and ORC Macro, 2006.

12. Masatu MC, Klepp K, Kvålea G. Use of health services and reported satisfaction among primary school adolescents in Arusha, Tanzania. Journal of Adolescent Health, 2001, 28(4), 278287.

13. Berhane F, Berhane $\mathrm{Y}$, Fantahun $\mathrm{M}$. Adolescents' health service utilization pattern and preferences: Consultation for reproductive health problems and mental stress are less likely. Ethiopian Journal of Health Development, 2005;19(1):29-36.

14. Worku S, Fantahun M. Unintended pregnancy and induced abortion in a town with accessible family planning services: The case of Harar in eastern Ethiopia. Ethiopian Journal of Health Development; 2006;20(2):79-83.

15. Tessema F, Asefa M, Ayele F. Mothers' Health Services Utilization and Health Care Seeking Behavior During Infant Rearing: A Longitudinal Community Based Study, South West Ethiopia. Ethiopian Journal of Health Development, 2002;16 (Special Issue):51-58.

16. Winston $M$, Patel V. Use of traditional and orthodox health services in urban Zimbabwe. International Journal of Epidemiology, 1995; 24: 1006-1012.

17. EPHA proceedings. Adolescent reproductive health, EPHA, Addis Ababa November 7-9 2003. 
18. Barbin L, Kemp J, Obunge OK, et.al. Reproductive tract infections and abortion among adolescent girls in rural Nigeria. Lancet, 1994; 345: 300-04.

19. Kebede Y. Contraceptive prevalence in Dembia District, northwest Ethiopia. Ethiopian Journal of Health Development, 2006; 20(1):32-38.

20. Nigussie M, Haile Mariam D, Mitike G. Assessment of safe delivery service utilization among women of childbearing age in north Gondar Zone, north west Ethiopia. Ethiopian Journal of Health Development, 2004; 18(3):145-153.

21. Seifu A, Fantahun M, Worku A. Reproductive health needs of out-of-school adolescents: A cross-sectional comparative study of rural and urban areas in northwest Ethiopia. Ethiopian Journal of Health Development, 2006;20(1):1017.
22. Habte D, Deyessa N, Davey G. Assessment of the Utilization of Pre-marital testing services and determinants of VCT in Addis Ababa. Ethiopian Journal of Health development, 2006; 20(1): 18-23.

23. Brieger WR, Delano GE, Lane CG, Oladepo O, Oyediran KA. West African Youth Initiative: Outcome of a Reproductive Health Education Program. Journal of Adolescent Health, 2001;29:436-446.

24. Erulkar AS, Mekbib T, Simie N, Gulema T. Differential use of adolescent reproductive health programs in Addis Ababa, Ethiopia. Journal of Adolescent Health, 2006: 38(3):253260.

25. Speizer IS, Magnani RJ, AND Colvin CE. The Effectiveness of Adolescent Reproductive Health Interventions in Developing Countries: A Review of the Evidence. Journal of Adolescent Health, 2003;33:324-348. 